\title{
Development of Feed-Forward Back-Propagation Neural Model to Predict the Energy and Exergy Analysis of Solar Air Heater
}

\author{
Harish K. Ghritlahre* \\ Department of Mechanical Engineering, National Institute of Technology, Jamshedpur, Jharkhand, \\ 831014, India
}

Received June 27, 2018; Accepted August 23, 2018; Published August 27, 2018

\begin{abstract}
In the present work, Artificial Neural Network (ANN) model has been developed to predict the energy and exergy efficiency of a roughened solar air heater $(\mathrm{SAH})$. Total fifty data sets of samples, obtained by conducting experiments on SAHs with three different specification of wire-rib roughness on the absorber plates, have been used in this work. These experimental data and calculated values of thermal efficiency and exergy efficiency have been used to develop an ANN model. LevenbergMarquardt (LM) and Scaled Conjugate Gradient (SCG) learning algorithm were used to train the proposed ANN model. Six numbers of neurons were found with LM learning algorithm in the hidden layer as the optimal value on the basis of statistical error analysis. In the input layer, the time of experiments, mass flow rate, ambient temperature, mean temperature of air, absorber plate temperature and solar radiation intensity have been taken as input parameters; and energy efficiency and exergy efficiency have been taken as output parameters in the output layer. The 6-6-2 neural model has been obtained as the optimal model for prediction. Performance predictions using ANN were compared with the experimental data and a close agreement was observed. Statistical error analysis was used to evaluate the results.
\end{abstract}

Keywords: Solar air heater; Energy analysis; Exergy analysis; Artificial Neural Network; Multi-layer perceptron

\section{Introduction}

In view of limited reserves of fossil fuels on the earth, it is necessary to develop efficient systems to use alternative sources of energy. Many types of renewable energy are available on the earth, in which solar energy is one of the most abundant and clean sources of energy. Solar energy can be utilized in two ways: active and passive. In passive solar energy utilization, sun rays are directly used without the aid of any equipment. In the active way of utilization of solar energy, sun rays are not directly used, and some kind of mechanical equipment is needed for conversion of the solar energy into other forms of energy. Solar air heater (SAH) comes in the category of active solar energy utilization.

In solar air heating systems, the solar collector or absorber plate is the main component which collects the solar energy in form of thermal energy and transfers the same to flowing air through the SAH duct. Due to the low heat capacity of flowing air, 
the convective heat transfer coefficient between the absorber plate and air is low. Hence, the main aim is to increase the heat transfer coefficient and thereby the heat flow rate. This objective can be achieved by using extended surfaces [1] or artificial roughness [2-5] on the absorber plate on the air flow side, or porous heat absorbing materials in the air flow duct of SAH [6,7].

In the present work, concepts of energy and exergy analyses have been used for evaluating the performances of roughened absorber plate SAH by ANN modeling. The quantitative energy analysis of any system is based on first law of thermodynamics, whereas the qualitative analysis is based on second law of thermodynamics. In recent years many researchers have carried out energy and exergy analyses of thermal systems. A mathematical model was developed by Ajam et al. [8] to study the exergetic performance of SAHs and optimize the system by using MATLAB. Esen [9] conducted experiments on double flow SAH with different obstacles on the absorber plate and did the energy and exergy analysis. Akpinar et al. [10] also used the concept of energy and exergy analysis for solar air heating unit with four different types of absorber plate with obstacles and without obstacles. Alta et al. [11] conducted experiments to investigate the energy and exergy analysis of 3 different types of SAHs. Bayrak et al. [12] performed energy and exergy analysis for porous bed SAH. Panwar et al. [13] reviewed energy and exergy analysis for solar drying systems. Saidur et al. [14] used the concept of energy and exergy analysis for various solar energy utilized equipment and concluded that exergy analysis is necessary to examine the system performance. Kumar et al. [15] conducted experiments on packed bed SAH for various mass flow rates of air and for different porosities of packing material and evaluated exergy of the system. Park et al. [16] studied the energy and exergy analysis of different types of renewable energy systems.

The performance analysis of solar air heaters using experimental and analytical study takes more time to solve problems and requires programming for solving in conventional software in analytical approach. Now a day, soft computing technique is attracting researchers for solving various complicated problems of nonlinear nature. The traditional approaches for such analysis cannot be solved without using fundamental equations, conventional correlations, or developing unique designs from experimental data through trial and error. To avoid these problems, artificial neural network (ANN) technique has been implemented in various types of complicated problems which are not solved by conventional method and in various fields. This technique computes data with very less time and more accurately predicted. Therefore, this technique has been becoming increasingly popular in Science and Engineering, especially in Thermal Engineering applications in recent years. Many researchers have used ANN in the past.

Kalogirou [17] used neural network in renewable energy systems to predict solar radiation and wind speed, and also for load forecasting of PV and building service systems. Yang et al. [18] have applied ANN technique for the heating system in building. They constructed optimal ANN model and predicted the room temperature by using experimental data. Facao et al. [19] used ANN for plate and tube type heat pipe hybrid solar collector. They constructed two different types of ANN model by use of multilayer perceptron (MLP) and radial basis function (RBF), and predicted the collector efficiency and useful heat gained. They found that the MLP model performed slightly better than 
the RBF model. Ertunc and Hosoz [20] used ANN for performance analysis of refrigeration unit. They constructed a 5-4-5 neuron model using experimental data and successfully predicted performance parameters such as power absorbed by refrigerant, compressor input power, mass flow rate of refrigerants, heat rejection rate of condenser and coefficient of performance (COP) of refrigeration unit. Kalogirou [21] applied ANN for predicting performance parameters of flat plate collector. To predict these parameters, he constructed six different types of ANN model on the basis of measured experimental data and got satisfactory results. Yilmaz and Atik [22] used ANN in a mechanical cooling system. They conducted experiments with different flow rates of cooling water and determined the power consumption, thermal performance, COP of heating and cooling. By using experimental data and calculated values they constructed an ANN model with 1-6-4 neurons to predict the power consumption, thermal efficiency, COP of heating and cooling. Sozen et al. [23] conducted experiments on flat plate SAH and calculated the thermal efficiency. By the use of experimental and calculated data optimal ANN was constructed using 7-20-20-1 and predicted the thermal efficiency with satisfactory results. Kurt et al. [24] conducted an experiment on solar cooker with various working conditions and collected the data. By the use of this data sample they constructed an ANN model to predict the enclosure air, pot water and absorber plate temperature of hot box type solar cooker with very less errors. Caner et al. [25] used ANN for estimating the thermal efficiency of solar air collector. Experiments were performed with two types of zigzagged absorber plat in SAH and collected the data for five days for constructing ANN model designed on the LM learning algorithm in nftool tool module in MATLAB. They found on the basis of statistical error analysis that the predicted thermal efficiency obtained by ANN model was reliable and accurate. Nazghelichi et al. [26] conducted experiments with different air temperatures, bed width and square cubed: carrot, collected total 518 data and determined energy and exergy of carrot cubes in fluidized bed dryer. By the use of this data they constructed an ANN model, and successfully predicted energy and exergy with minimum errors. Aghbashlo et al. [27] applied ANN for estimating the exergetic behavior of spray drying. The data was obtained from the experiments. They used optimum ANN model on the basis of minimum error and maximum $\mathrm{R}^{2}$ value, and successfully predicted the exergetic performance of the unit by the use of this model. Benli [28] also applied ANN technique for determining the thermal efficiency of SAH with trapeze and corrugated absorber plate. For estimating the collector efficiency, experiments were performed, and data was collected for developing of ANN model with LM learning algorithms. The ANN predicted results on thermal performance of solar air collector, which were found accurate with LM-3 neurons in hidden layer. Kalogirou et al. [29] applied ANN for predicting the performance of large solar systems. For predicting the performance, ANN model was constructed on measured experimental data of over one year and successfully predicted results with higher coefficient of determinations. Hamdan et al. [30] developed a 5-20-5 multiple output parameter NARX neural model to predict the heat transfer analysis of flat plate solar air collector. Jani et al. [31, 32] used ANN technique to predict the performance of a solid desiccant - vapor compression hybrid air-conditioning system. Ghritlahre and Prasad [33-40] implemented MLP neural model to predict the performances of various types of solar air heaters. 
From the literature, it has been found that the ANN technique is used for performance analysis of various types of thermal systems, but very few work in the field of solar systems, especially in the topic of solar air heater performance analysis. In the view of above the energy and exergy analysis of solar air heater, using MLP neural model is new research work and has been taken in the present work.

The aim of this work is to predict the energy efficiency and the exergy efficiency of solar air heaters using the ANN model on the basis of actual experimental data and the calculated values. Total fifty sets of data have been obtained by conducting experiments on three types of transverse wire rib roughened solar air heaters. The ANN model consists of six variables in the input layer and two variables in the output layer. Two different types of training functions with 4-7 neurons have been used to obtain the best network for prediction of output parameters. Six neurons in the hidden layer with LM learning function is obtained as an optimal topology. Statistical error analysis has been performed for predicted values of energy and exergy efficiency.

\section{Materials and Methods}

\section{Experimental System and Data Collection}

The line diagram of the experimental system is shown in Fig. 1. The system consists of an artificial roughened SAH having entrance section, test section, exit section, absorber plate and glass cover and equipped with galvanized iron (GI) pipe, flange coupling, orifice plate, U-tube manometer, thermometers, a suction blower, a valve and a Variac transformer. In the present work, the SAH duct length is $168 \mathrm{~cm}$, width is $28 \mathrm{~cm}$ and height is $4 \mathrm{~cm}$. The test section is a rectangular duct having wire- roughened absorber plate and a back plate. It consists of a $4 \mathrm{~mm}$ thick glass cover at its top. Fig. 2 shows the structure of the test section. The absorber plate is made of $1 \mathrm{~mm}$ thick GI sheet provided with transvers wire of three different specifications as given in Table 1. A configuration of wire-roughness used on the absorber plate has been shown in Fig. 3a, where as a photographic view of the same has been given in Fig. 3b. The test section is connected with 3 inch diameter GI pipe provided with an Orifice meter to measure the mass flow rate of air through the SAH. The pressure drop was measured with the help of a U-tube Manometer fitted across the orifice plate. The mass flow rate was varied from 0.0235 to $0.0270 \mathrm{~kg} / \mathrm{sec}$. A $2 \mathrm{HP} / 3$-phase suction blower was used to carry air through the SAH duct. The intensity of solar radiation was measured with a digital pyranometer. For measuring the temperature at various sections of absorber plate and air temperatures at inlet and outlet, digital thermometers were used. The experiments were conducted in clear sky in the month of April 2014 and data were taken from 10:30 am to 1:00 pm. Total 50 sets of experimental data were collected from experiments with three different types of roughened absorber plate, categorised on the basis of roughness height (e), relative roughness pitch $(\mathrm{P} / \mathrm{e})$ and relative roughness height $(\mathrm{e} / \mathrm{D})[5]$.

The experiments were conducted in Jamshedpur (India), where latitude and longitude are $22.77^{\circ} \mathrm{N} \& 86.14^{\circ} \mathrm{E}$, respectively. The variation of wind speed and solar intensity of radiation with different months of the year, obtained at Jamshedpur from RETScreen database, have been shown in Fig. 4 and Fig. 5, respectively. Fig.5 shows that 
the maximum solar energy of $6.21 \mathrm{kwh} / \mathrm{m}^{2} /$ day is obtained in the month of April, and the lowest solar energy of $3.95 \mathrm{kwh} / \mathrm{m}^{2} /$ day is obtained in the month of August. Air temperature is recorded maximum in the month of May, which is $32^{\circ} \mathrm{C}$ and minimum in January, which is $18^{\circ} \mathrm{C}$. The gross incident solar radiation has been estimated as 1744.7 $\mathrm{kwh} / \mathrm{m}^{2} /$ year.

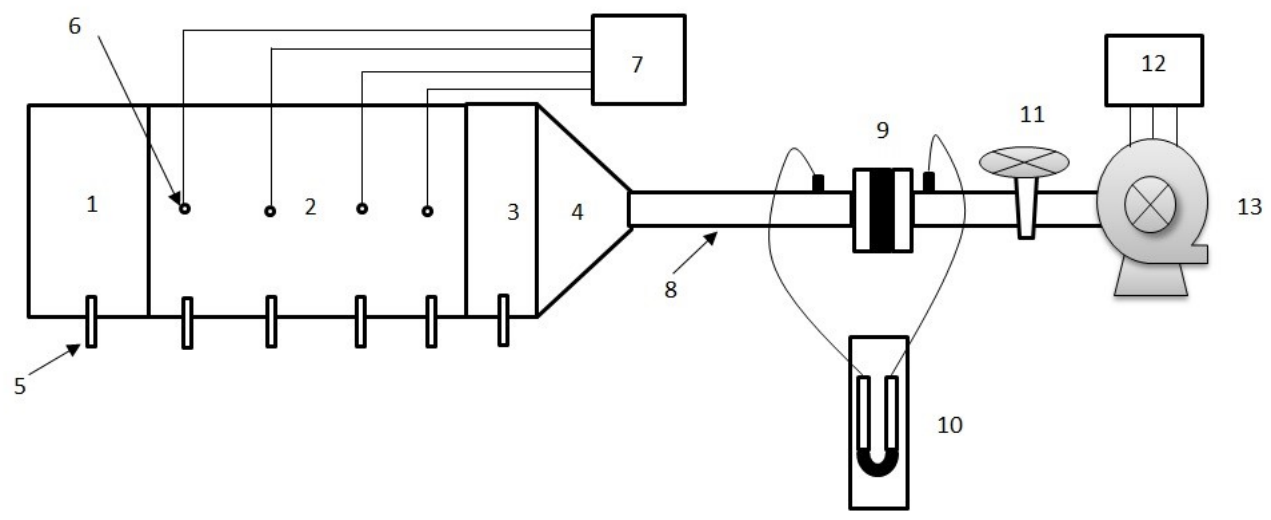

Figure 1. Experimental system

1. Entrance section

2. Test section

3. Exit section

4. Diverging section

5. Digital thermometer

6. Thermocouples

7. Temperature display unit
8. GI pipe

9. Orifice plate

10. U-tube manometer

11. Valve

12. Variac transformer

13. Suction blower

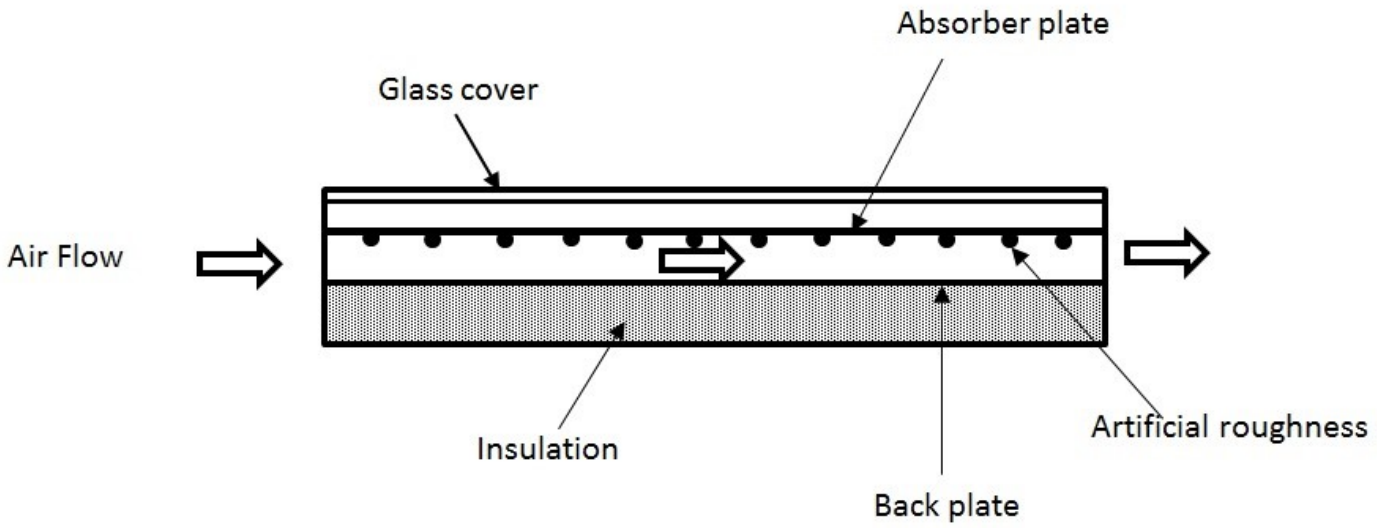

Figure 2. Test section 


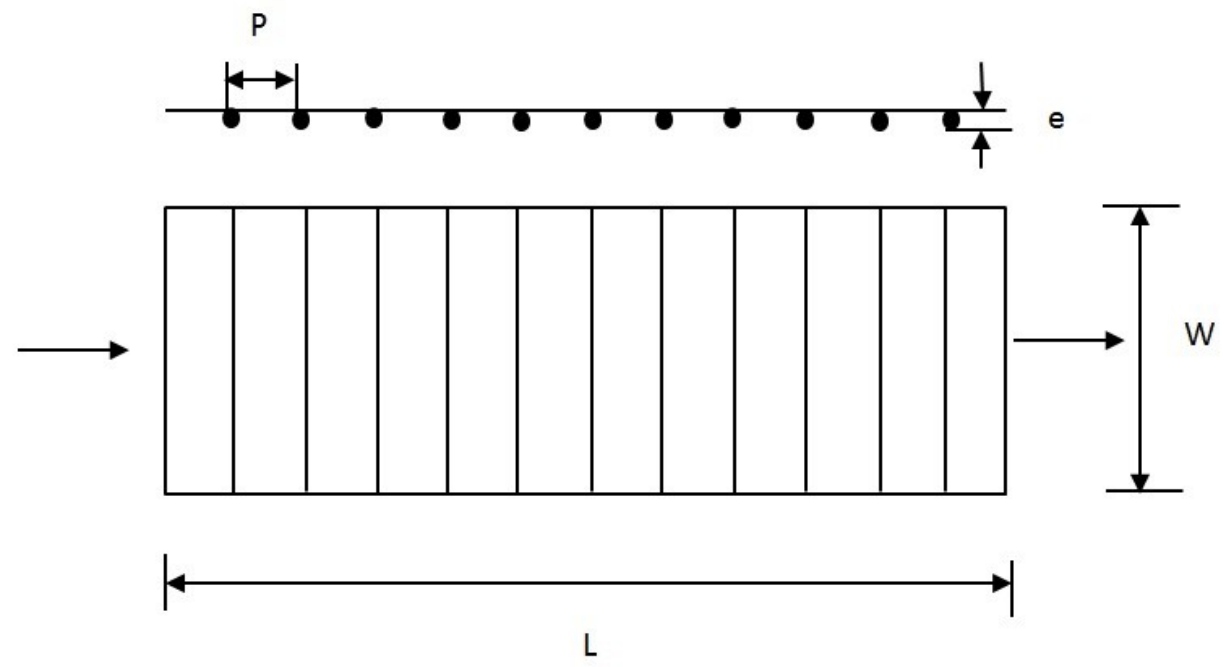

Figure 3a. Wire roughened Absorber plate

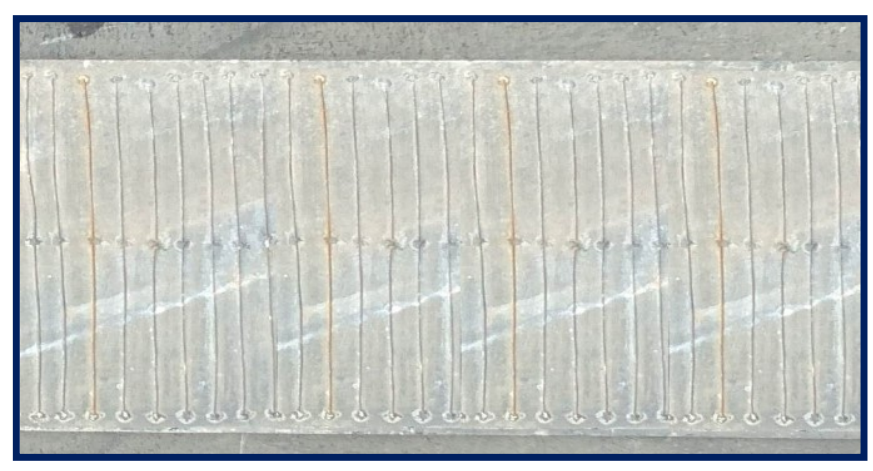

Figure 3b. Photographic view of absorber plate

Table 1. Specification of wire roughness.

\begin{tabular}{lccc}
\hline Roughness parameter & \multicolumn{3}{c}{ Absorber roughness type } \\
\cline { 2 - 4 } & Type A & Type B & Type C \\
\hline Relative roughness pitch (P/e) & 10 & 10 & 10 \\
Relative roughness height (e/D) & 0.014 & 0.01740 & 0.009571 \\
Roughness height (e), mm & 0.98 & 1.2 & 0.67 \\
\hline
\end{tabular}




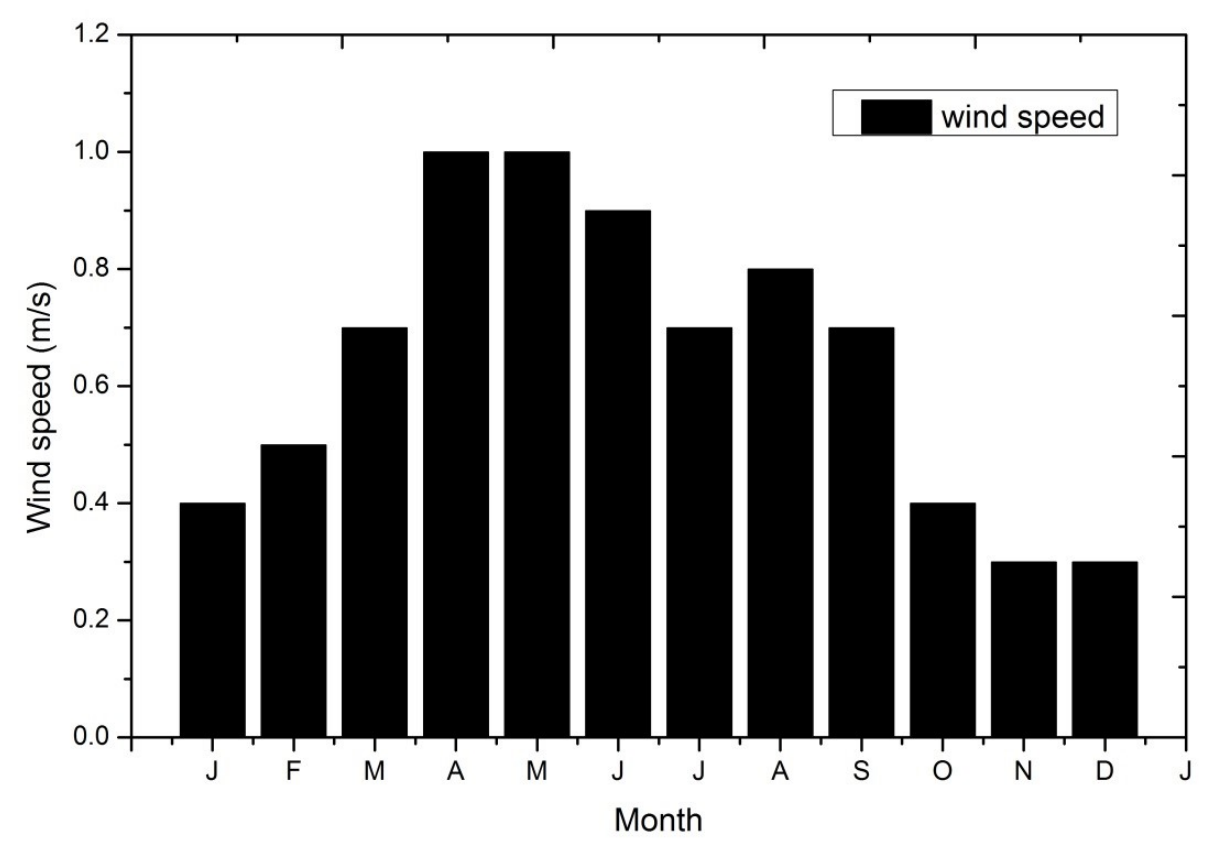

Figure 4. Local weather graph showing wind speed in different months of a year.

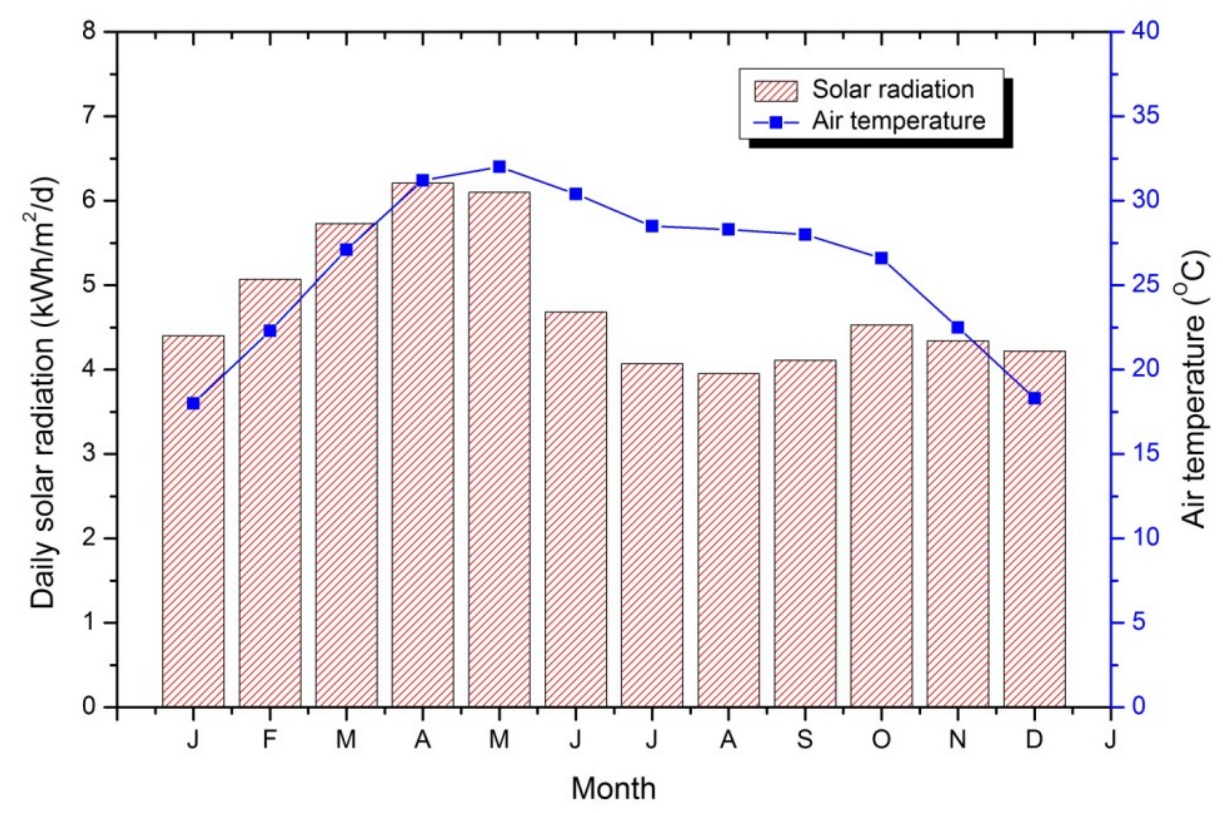

Figure 5. Local weather graph showing intensity of solar radiation and air temperature in different months of a year. 


\section{Energy and Exergy Analysis}

\section{Analysis of Energy}

Energy analysis of a SAH is represented by its thermal efficiency, which is defined as the ratio of energy gained to incident solar radiation [1] and is given as

$$
\eta_{t h}=\frac{\dot{Q}_{u}}{\dot{Q}_{c}}
$$

where $Q_{u}$ is the useful heat gain and the incident radiation of solar energy $Q_{c}$ is given by

$$
\dot{Q}_{c}=I A_{c}
$$

In Eq. (2), $I$ is solar radiation intensity and $A_{c}$ is collector area.

The useful energy gained by air is written as

$$
\dot{Q}_{u}=\dot{m} C_{p} \cdot \Delta T_{f}=\dot{m} C_{p}\left(T_{f o}-T_{f i}\right)
$$

where $m$ is the mass flow rate of air, $T_{f o}$ and $T_{f i}$ are outlet and inlet temperature of air respectively.

Thus, the thermal efficiency of collector is [1]:

$$
\eta_{t h}=\frac{\dot{Q}_{u}}{I A_{c}}
$$

\section{Analysis of Exergy}

The analysis of exergy is the most useful concept for optimal utilization of energy. This analysis is used to make strategies for designing and operation of industrial processes. The exergetic efficiency is defined as the ratio of exergy gained from the system to exergy input to the system [40].

Following assumptions have been undertaken in the present analysis:

(i) The system works under the steady state condition.

(ii) Kinetic Energy and Potential Energy are negligible.

(iii) Chemical and nuclear reactions are not possible to occur in operation of the system.

(iv) The air specific heat is constant and it is considered as an ideal fluid.

(v) The heat transfer to the system and work transfer from the system are positive

In general, energy and exergy balance equations in rate form with negligible kinetic and potential energies can be written as $[11,12,16,42]$ :

$$
\begin{aligned}
& \sum \dot{E}_{i}=\sum \dot{E}_{o} \\
& \sum \dot{E x_{i}}-\sum \dot{E \dot{x}_{o}}=\sum \dot{E \dot{x}_{d}}
\end{aligned}
$$




$$
\sum \dot{E x}_{\text {heat }}-\sum \dot{E} \dot{x}_{\text {work }}+\sum \dot{E} \dot{x}_{\text {mass, in }}-\sum \dot{E} \dot{x}_{\text {mass }, \text { out }}=\sum \dot{E} \dot{x}_{\text {dest }}
$$

In Eqs. (5) to (7), $\dot{E}$ and $\dot{E x}$ are energy and exergy rates, respectively. $E x_{\text {dest }}$ is the rate of exergy destruction, $i$ and $o$ stand for inlet and outlet of the system, respectively.

By introducing temperature of environment $T_{e}$, sun surface temperature $T_{s}$, energy gained by collector $Q_{c}$, work rate $\dot{W}$, and the specific exergy $\psi$ in Eq. (7), the resulting equation becomes:

Eq. (7) can also be expressed in the form of general exergy equation as given below:

$$
\sum\left(1-\frac{T_{e}}{T_{s}}\right) \dot{Q_{c}}-\dot{W}+\sum \dot{m}_{i} \psi_{i}-\sum \dot{m}_{o} \psi_{o}=\sum \dot{E} \dot{x}_{\text {dest }}
$$

Where,

$$
\begin{aligned}
& \psi_{i}=\left(h_{i}-h_{e}\right)-T_{e}\left(s_{i}-s_{e}\right) \\
& \psi_{o}=\left(h_{o}-h_{e}\right)-T_{e}\left(s_{o}-s_{e}\right)
\end{aligned}
$$

In Eqs. (9) and (10), h is enthalpy and $\mathrm{s}$ is entropy, suffix $e$ stand for environment.

From Eq.(8),(9) and (10), the expression:

$$
\left(1-\frac{T_{e}}{T_{s}}\right) \dot{Q}_{c}-\dot{m}\left[\left(h_{o}-h_{i}\right)-T_{e}\left(s_{o}-s_{i}\right)\right]=\sum \dot{E} \dot{x}_{\text {dest }}
$$

Where,

$$
\dot{Q}_{C}=I A_{C}
$$

The change in the enthalpy and the entropy of the air

$$
\begin{aligned}
& \Delta h_{\text {air }}=h_{o}-h_{i}=C_{p f}\left(T_{f o}-T_{f i}\right) \\
& \Delta s_{a i r}=s_{o}-s_{i}=C_{p f} \ln \frac{T_{f o}}{T_{f i}}-R \ln \frac{P_{o}}{P_{i}}
\end{aligned}
$$

In Eqs. (13) and (14), $C_{p f}$ is specific heat of air ( $\left.\mathrm{J} / \mathrm{kg} \mathrm{K}\right), T_{f i}$ and $T_{f o}$ are inlet and outlet air temperatures, respectively, and $R_{a}$ is Universal gas constant $(\mathrm{J} / \mathrm{kg} \mathrm{K})$.

From Eq.(11) to (14) the following expression can be obtained:

$$
\left(1-\frac{T_{e}}{T_{s}}\right) I A_{c}-\dot{m} C_{p f}\left(T_{f_{o}}-T_{f i}\right)+\dot{m} T_{e}\left(C_{p f} \ln \frac{T_{f o}}{T_{f i}}-R_{a} \ln \frac{P_{o}}{P_{i}}\right)=\sum \dot{E} \dot{x}_{\text {dest }}
$$

where $P$ is the pressure of air.

The Irreversibility/exergy destruction may be expressed as follows:

$$
\dot{E x_{\text {dest }}}=T_{e} \cdot \dot{S}_{\text {gen }}
$$

where $S_{g e n}$ is the rate of entropy generation. 
The exergy efficiency of SAH can be formulated by the ratio of net exergy output of the system to exergy input of the system.

$$
\eta_{I I}=\frac{\dot{E} x_{o}}{\dot{E} x_{i}}=\frac{\dot{m}\left[\left(h_{o}-h_{i}\right)-T_{e}\left(\mathrm{~s}_{o}-s_{i}\right)\right]}{\left(1-\frac{T_{e}}{T_{S}}\right) I A_{c}}
$$

\section{Artificial Neural Network (ANN)}

ANN is a complex information processing system, which is structured from interconnected segmental processing elements, called neurons. These neurons find the input information from other sources and perform generally a non-linear operation on the result and then give final results as output. ANN works in two ways, first learning and then storing the knowledge in interconnects called weights. The basic model of ANN is represented in Fig. 6. ANN is a simulation tool in MATLAB which can be used to estimate the values on the basis of input parameters, optimum topology and training processes. In feed forward networks, each product of input elements and weights are fed to summing junctions and is summed with bias of neurons as follows $[17,32,41]$ :

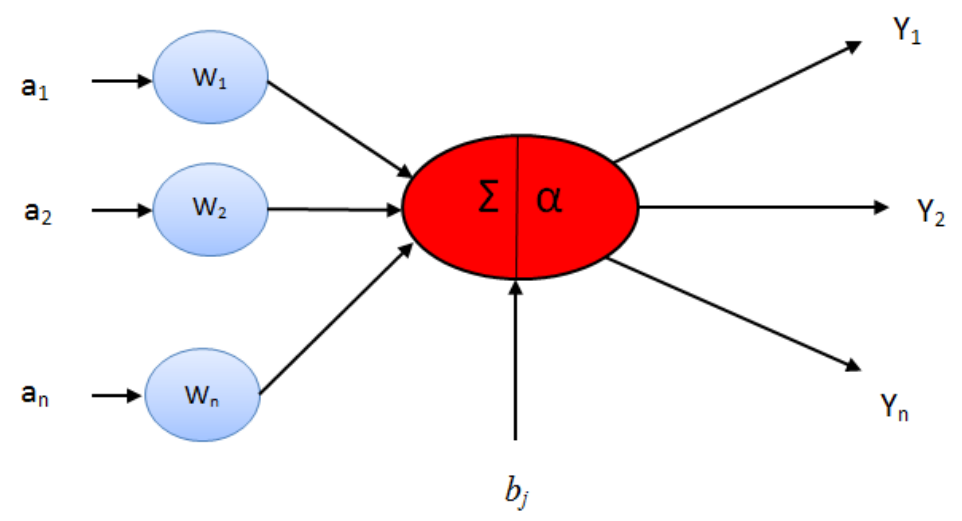

Figure 6. Basic structure of ANN model

$$
X=\left(\sum_{i=1}^{n} w_{i j} a_{i}\right)+b_{j}
$$

Then this sum $\mathrm{X}$ passes through transfer function $F$ which generates an output.

$$
F(X)=u_{j}=F\left[\left(\sum_{i=1}^{n} w_{i j} a_{i}\right)+b_{j}\right]
$$


The most used transfer functions in the hidden layer are tansig and logsig. The nonlinear activation function, which is widely used, is called as sigmoid function whose output lies in between 0 and 1 , and it is given as:

$$
F(X)=\frac{1}{1+e^{-X}}
$$

The performance index of different training algorithm is mean square error (MSE) and it is formulated as

$$
M S E=\frac{1}{n} \sum_{i=1}^{n}\left(X_{A, i}-X_{P, i}\right)^{2}
$$

where $X_{A}$ and $X_{P}$ are actual value and predicted value, respectively.

\section{Selection Criteria for Optimal ANN Model}

The optimal ANN model to predict the exergetic performance is based on the criteria of selection of minimum errors of root mean square error (RMSE), mean absolute error (MAE) and best fit of ANN predicted data with experimental data on the basis of coefficient of determination $\left(\mathrm{COD}, \mathrm{R}^{2}\right)$.

Root mean square error (RMSE):

$$
R M S E=\sqrt{\frac{1}{n} \sum_{i=1}^{n}\left(X_{A, i}-X_{P, i}\right)^{2}}
$$

Mean absolute error (MAE):

$$
M A E=\frac{1}{n} \sum_{i=1}^{n}\left(X_{A, i}-X_{P, i}\right)
$$

Coefficient of determination (COD):

$$
R^{2}=1-\frac{\sum_{i=1}^{n}\left(X_{A, i}-X_{P, i}\right)^{2}}{\sum_{i=1}^{n} X_{P, i}^{2}}
$$

\section{Modeling of ANN Structure}

\section{Neural Structure Development}

In the present analysis, total 50 sets of experimental data were collected by conducting experiments for 10 days. The proposed MLP ANN model for prediction of energy and exergy analyses is shown in Fig. 7, which was structured with an input layer, hidden layer and output layer. Six parameters in the input layer including time of experiments, mass flow rate of air, atmospheric temperature, air mean temperature, plate temperature and solar intensity, and two parameters of thermal efficiency and exergy efficiency in output layer have been taken. The ranges indicating the minimum and maximum values of input and output parameters are listed in Table 2. 


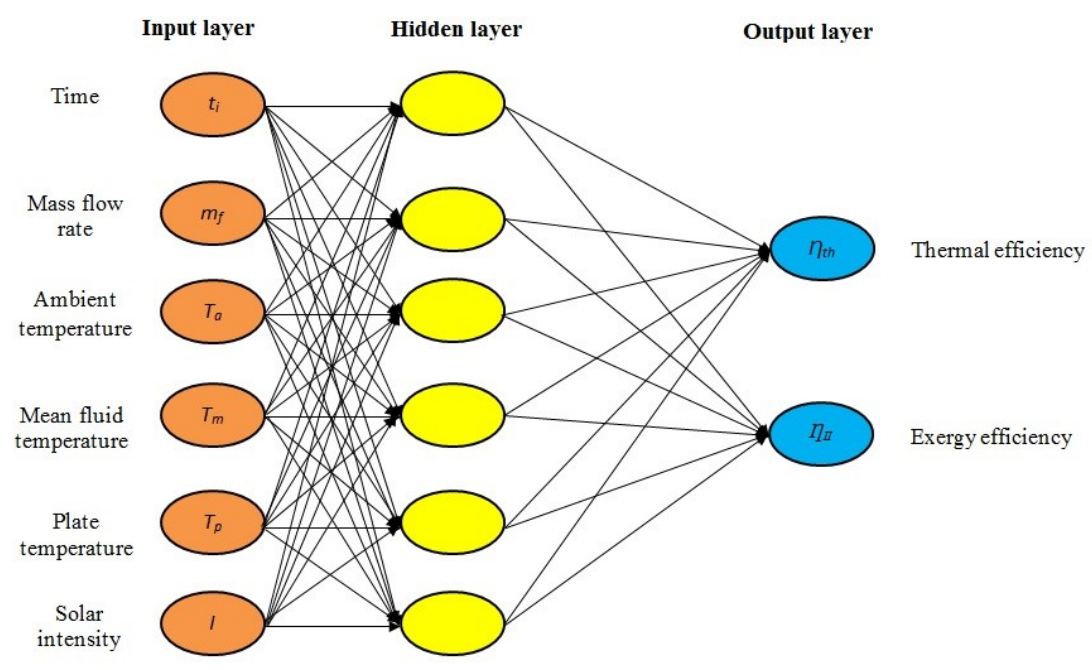

Figure 7. Present ANN model

Table 2. Minimum and maximum values of input and output parameters for ANN Model

\begin{tabular}{|l|c|c|}
\hline Parameters & \multicolumn{2}{|c|}{ Range } \\
\hline Input & Minimum value & Maximum value \\
\hline Mass flow rate of air, $m_{f}(\mathrm{~kg} / \mathrm{sec})$ & 0.0235 & 0.0270 \\
\hline Atmospheric temp. $T_{a}\left({ }^{\circ} \mathrm{C}\right)$ & 32 & 42 \\
\hline Mean temp. of air, $T_{m}\left({ }^{\circ} \mathrm{C}\right)$ & 38 & 47.5 \\
\hline Absorber Plate temp. $T_{p}\left({ }^{\circ} \mathrm{C}\right)$ & 63.2 & 73.40 \\
\hline Solar Intensity, $I\left(\mathrm{~W} / \mathrm{m}^{2}\right)$ & 833 & 905 \\
\hline Output & & 47.9937 \\
\hline Thermal efficiency, $\eta_{t h}(\%)$ & 25.6843 & 0.7906 \\
\hline Exergy efficiency, $\eta_{I I}(\%)$ & 0.3829 & \\
\hline
\end{tabular}

\section{Data Preparation}

For this model, 50 data sets have been taken out, in which $70 \%$ data is designed for training process and rest of 30\% data is taken for testing process. Feed forward back propagation learning algorithm has been applied for learning of present model. Single hidden layer was chosen in this model.

Before developing the ANN model, the input and output sample data must be normalized between -1 and 1 for accuracy of prediction. The following equation is used to normalize data between -1 and 1 .

$$
Y=\frac{Y_{i}-Y_{\min }}{Y_{\max }-Y_{\min }}\left(H i g h_{\text {value }}-L o w_{\text {value }}\right)+L o w_{\text {value }}
$$




\section{Selection of Learning Algorithm and Transfer Function}

For training process, 4-7 neurons have been selected in the hidden layer for the optimal network selection to obtain the best results. The two types of training functions are selected, which are Scaled Conjugate Gradient (SCG) and Levenberg-Marquardt (LM) algorithms. After selecting the training function the adaption learning function was selected (LEARNGDM). Tansig transfer function was selected for the hidden layer and linear function (purelin) for the output layer. This model is performed in MATLAB software using nntool for computation.

\section{Modelling Procedures}

In order to find the result, for predicting the performance parameters of SAHs, following steps are followed in MATLAB ANN simulation:

Step 1. Selection of nntool command.

The nntool for starting the neural network technique in MATLAB software is first selected.

Step 2. Selection of the input and target variables.

For structuring a neural model, mainly, the input and output variables from the experimental data and calculated values of solar air heater have been selected.

Step 3. Selection of training and testing data.

Out of total 50 data sets, $70 \%$ data is used for training process and $30 \%$ data is used for testing process.

Step 4. Selection of training function and adaption learning function.

In present work, two types of training functions are used such as TRAINLM and TRIANSCG, and the LEARNGDM is selected as adaption learning function.

Step 5. To choose the number of neurons and layers in the hidden layer with transfer functions.

The number of neurons is selected in the hidden layer by trial and error method, accordingly 4-7 number of neurons have been selected to obtain the best model for prediction. Single layer is used in the hidden layer. Tangent sigmoid (Tansig) and pure linear (purlin) transfer functions are used at hidden and output layer respectively.

Step 6. Training of the ANN model with experimental data.

Different number of neurons using TRAINLM and TRAINSCG for 50 times run for each model is trained.

Step 7. To check and compare the performance of different models.

To obtain the optimal model, different model training performance on the basis of RMSE, MAE and $\mathrm{R}^{2}$, which are calculated by using Eqs. (22), (23) and (24), respectively, is checked. The performance of training process of different models is shown in Table 3. 
Step 8. To select optimal ANN model.

It is found that LM algorithm with six neurons (LM-6) in the hidden layer is optimal model due to the lowest error and the highest value of $\mathrm{R}^{2}$ for energy and exergy efficiencies.

Step 9. To save the predicted results and to compare with actual available data.

Finally, the predicted results of thermal or energy efficiency and exergy efficiency are saved and compared with actual experimental data. The comparison of predicted results and their statistical error analysis is shown in Table 4.

The flow chart of ANN simulation is shown in Fig. 8, exhibiting all steps undertaken in the analysis.

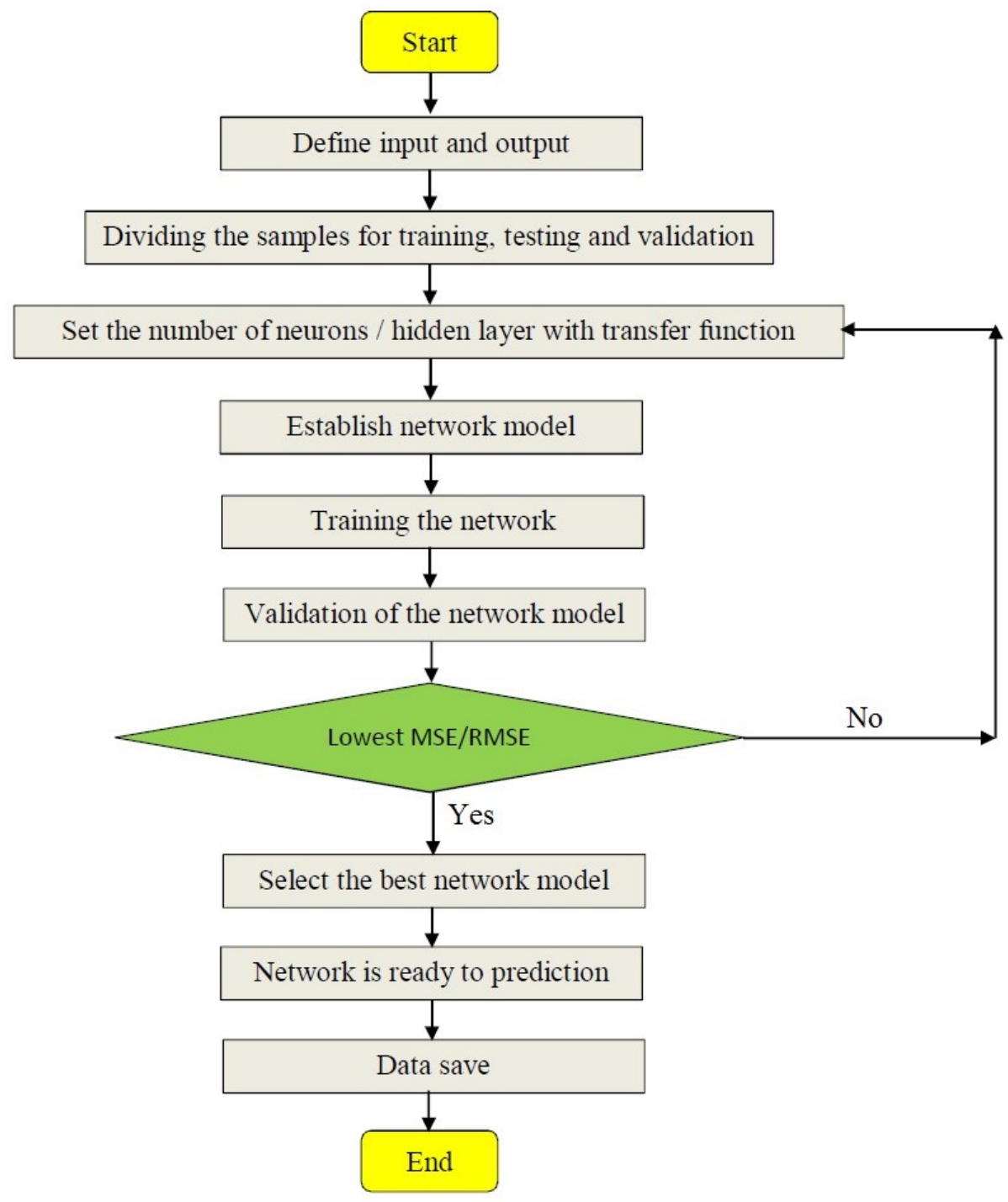

Figure 8. Flow chart of ANN simulation. 


\section{Results and Discussion}

In the optimal neural model, the training algorithm of LM with 6 neurons adjusted the weights and biases iteratively to minimize the error between actual and predicted values of ANN model.

The values of regression coefficient $(\mathrm{R})$ for training, validation, testing and all process are 1.0, 1.0, 0.99999 and 1.0, respectively (Fig. 9), which gives the accurate result. The best validation performance was found at 4 epoch at which the MSE during validation is found to be 0.022696 . Also training process stopped at epoch 54 because the minimum gradient error reached.
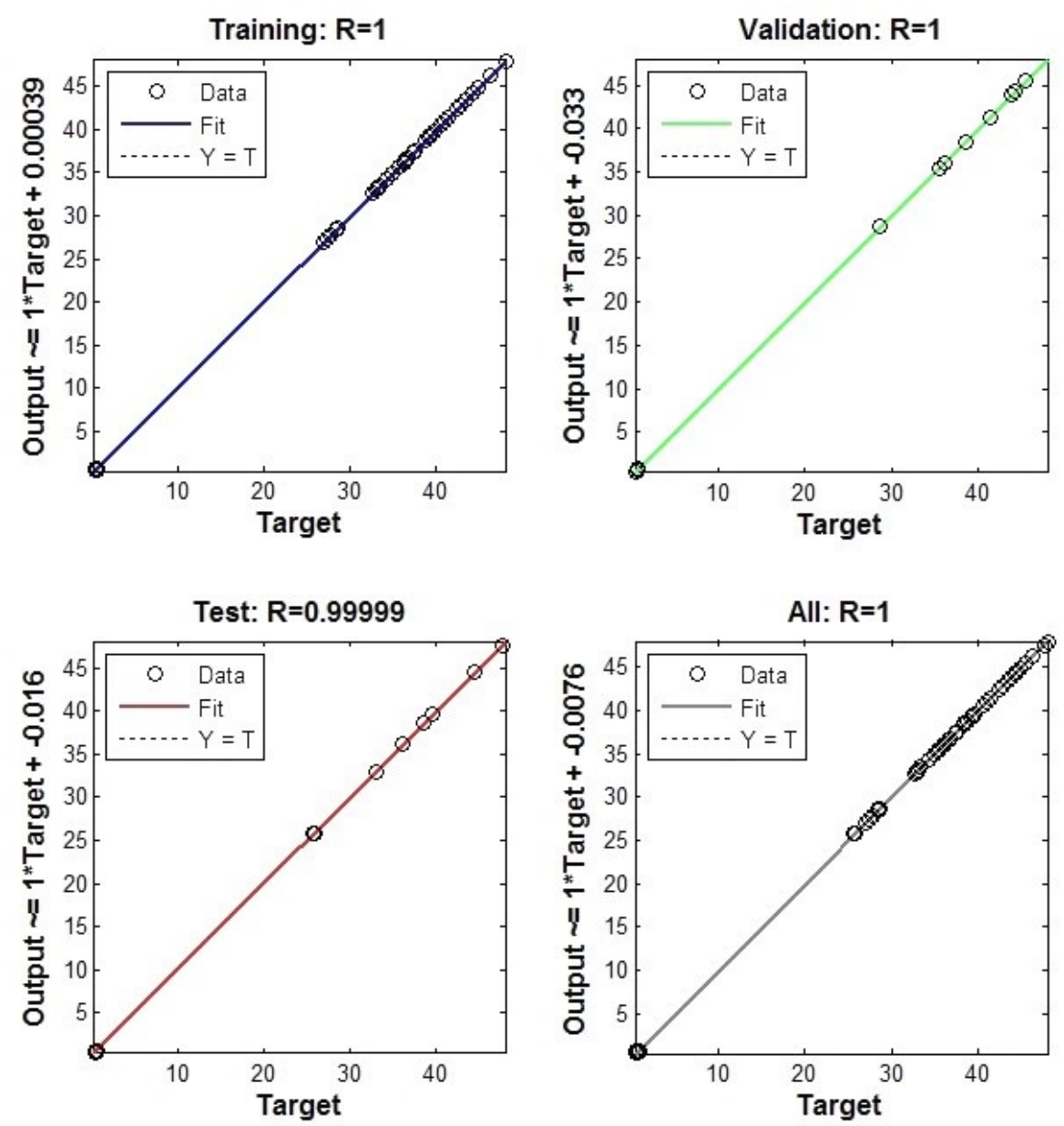

Figure 9. Regression plot of TRAINLM-6

A comparison between actual (experimental) data and predicted data from ANN model is shown in Fig. 10, while the absolute errors are shown in Fig. 11. As from Fig. 11 , it has been found that the errors between ANN predicted values and actual experimental values are very small. Table 4 shows the performance of selected LM-6 ANN model for estimating the energy and exergy efficiency on the basis of MAE, sum of square error (SSE), MSE, coefficient of variance (COV) and $\mathrm{R}^{2}$. The values of MSE, 
MAE and $\mathrm{R}^{2}$ are calculated by Eqs. (21), (23) and (24), respectively. The rest errors are calculated by using following formulas:

Sum of square error (SSE):

$$
S S E=\sum_{i=1}^{n}\left(X_{A, i}-X_{P, i}\right)^{2}
$$

Coefficient of variance (COV):

$$
C O V=\frac{R M S E}{\frac{1}{n} \sum_{i=1}^{n} X_{P, i}} \times 100
$$

Table 3. Statistical results of training process

\begin{tabular}{|l|c|c|c|c|}
\hline Parameters & $\begin{array}{c}\text { Training } \\
\text { Function }\end{array}$ & MAE & $\mathbf{R}^{\mathbf{2}}$ & RMSE \\
\hline Thermal efficiency, $\eta_{\text {th }}$ & LM-4 & 2.64395 & 0.99337 & 3.11437 \\
\cline { 2 - 5 } & SCG-4 & 2.40804 & 0.99384 & 2.99610 \\
\cline { 2 - 5 } & LM-5 & 1.23885 & 0.99787 & 1.77980 \\
\cline { 2 - 5 } & SCG-5 & 2.45031 & 0.99382 & 2.99867 \\
\cline { 2 - 5 } & LM-6 & $\mathbf{0 . 0 2 4 4 5}$ & $\mathbf{0 . 9 9 9 9 9}$ & $\mathbf{0 . 0 4 5 6 0}$ \\
\cline { 2 - 5 } & SCG-6 & 2.21554 & 0.99465 & 2.81480 \\
\cline { 2 - 5 } & LM-7 & 1.55907 & 0.99689 & 2.14564 \\
\cline { 2 - 5 } & SCG-7 & 1.92430 & 0.99534 & 2.62551 \\
\hline Exergy efficiency, $\eta_{I I}$ & LM-4 & 0.12917 & 0.93749 & 0.15481 \\
\cline { 2 - 5 } & SCG-4 & 0.10456 & 0.95916 & 0.13370 \\
\cline { 2 - 5 } & LM-5 & 0.08096 & 0.97094 & 0.09779 \\
\cline { 2 - 5 } & SCG-5 & 0.13626 & 0.94039 & 0.16690 \\
\cline { 2 - 5 } & LM-6 & $\mathbf{0 . 0 3 1 2 3}$ & $\mathbf{0 . 9 9 5 0 9}$ & $\mathbf{0 . 0 3 9 2 2}$ \\
\cline { 2 - 5 } & SCG-6 & 0.07991 & 0.96475 & 0.11359 \\
\cline { 2 - 5 } & LM-7 & 0.10223 & 0.95511 & 0.10032 \\
\cline { 2 - 5 } & SCG-7 & 0.16794 & 0.83109 & 0.20452 \\
\hline
\end{tabular}

From Table 4, it has been found that values of MAE, SSE, MSE and COV are $0.06220,1.3244,0.026488$ and 0.43471 , respectively, for thermal efficiency. Similarly, for exergy efficiency, these values are $0.014689,0.02257,4.514 \mathrm{E}-4$ and $0.36241 \mathrm{E}-1$, respectively. Also the values of $\mathrm{R}^{2}$ are 0.99921 and 0.95737 for thermal efficiency and exergy efficiency, respectively. 
The comparison of results of present work and those available in the literature is shown in Table 5. The comparisons are based on the value of $\mathrm{R}$ in training, testing, validation and all processes combined. It is clearly observed that the values of $\mathrm{R}$ of present work in training, testing, validation and all processes were the highest, as compared to previous work of ANN models based on single and multiple output parameters. The above results reveal that the ANN model accurately predicted the energy and exergy efficiencies of the solar air heater.

Table 4. Performance of proposed MLP ANN model predicting energy and exergy efficiencies.

\begin{tabular}{|l|c|c|c|c|c|}
\hline Parameters & MAE & SSE & MSE & COV & $\mathbf{R}^{2}$ \\
\hline Thermal efficiency, $\eta_{t h}$ & 0.06220 & 1.3244 & $2.648 \mathrm{E}-2$ & 0.43471 & 0.99921 \\
\hline Exergy efficiency, $\eta_{I I}$ & 0.01468 & 0.02257 & $4.514 \mathrm{E}-4$ & $0.362 \mathrm{E}-1$ & 0.95737 \\
\hline
\end{tabular}

Table 5. The comparisons of results of present work and those available in the literature.

\begin{tabular}{|l|c|c|c|c|c|}
\hline \multirow{2}{*}{ Authors } & \multirow{2}{*}{$\begin{array}{c}\text { Model } \\
\text { Structure }\end{array}$} & \multicolumn{4}{|c|}{ Statistical results } \\
\cline { 3 - 6 } & & Training & Validation & Testing & All \\
\hline & & R1 & R2 & R3 & R \\
\hline Caner et al. [25] & $8-20-1$ & 0.99998 & 0.99985 & 0.99995 & 0.99997 \\
\hline Hamdan et al. [30] & $5-20-5$ & 0.99997 & 0.99998 & 0.99996 & 0.99997 \\
\hline Ghritlahre and Prasad [33] & $5-5-3$ & 0.99985 & 0.99991 & 0.99958 & 0.9998 \\
\hline Ghritlahre and Prasad [37] & $6-6-1$ & 0.99994 & 0.99943 & 0.99453 & 0.99942 \\
\hline Present work & $6-6-2$ & 1 & 1 & 0.99999 & 1 \\
\hline
\end{tabular}




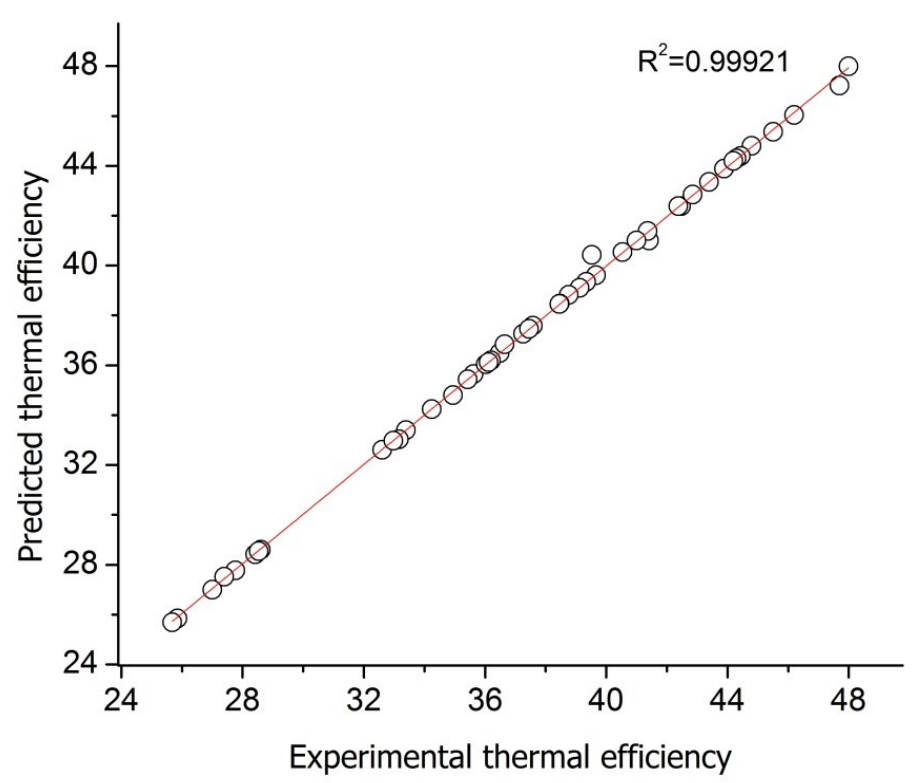

(a)

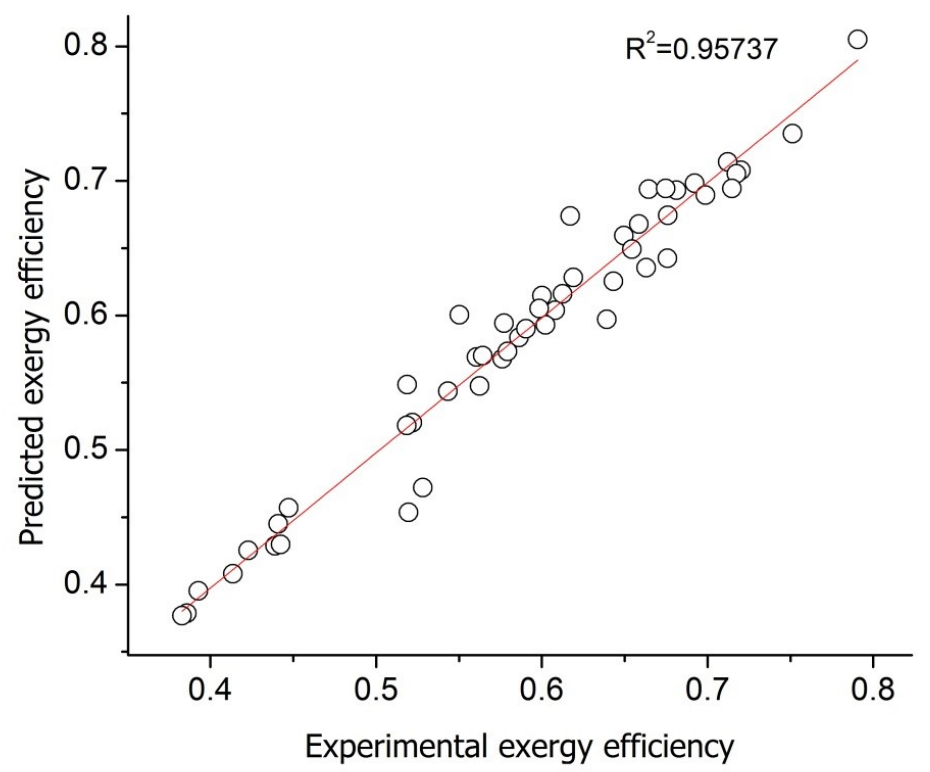

(b)

Figure 10. Comparison of experimental energy and exergy efficiency with ANN predicted energy and exergy efficiency. 


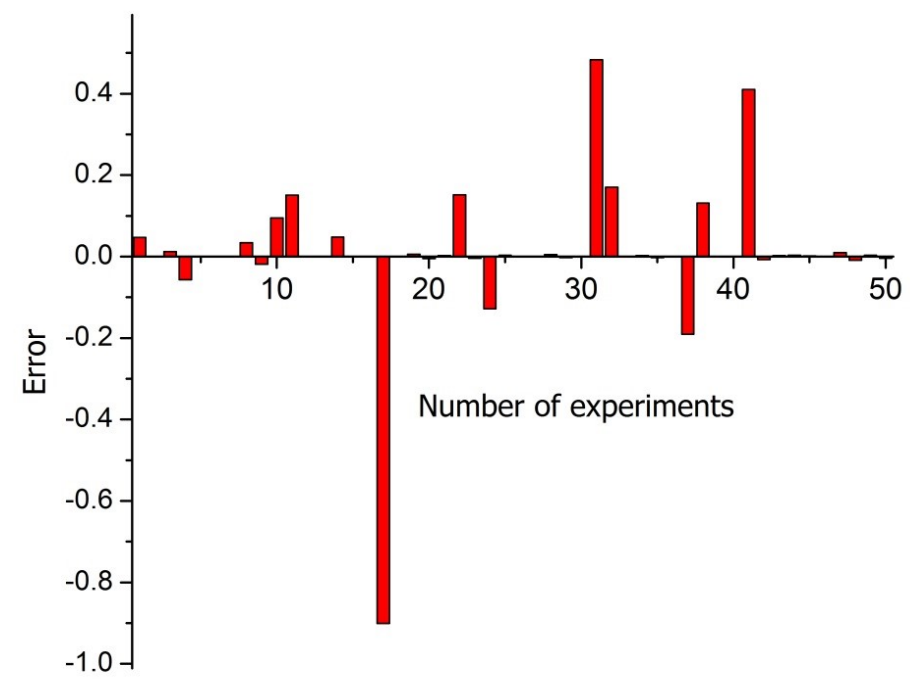

(a)

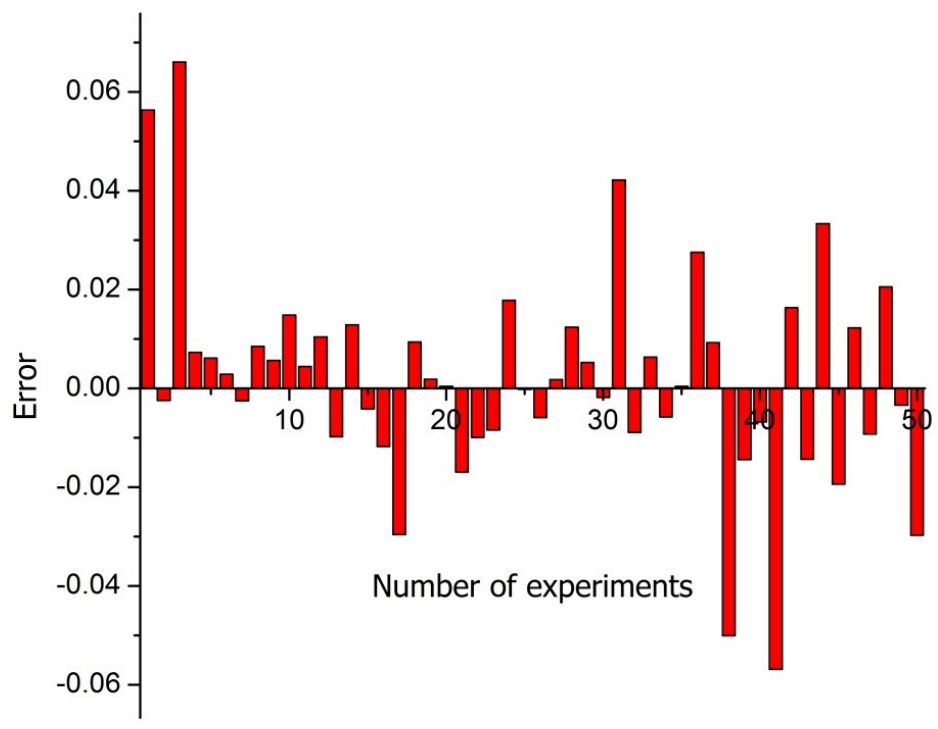

(b)

Figure 11. Absolute error for ANN predicted energy and exergy efficiency.

\section{CONCLUSIONS}

In this paper, ANN technique has been used to predict the energy and exergy efficiencies of roughened solar air heater. To achieve this objective, total 50 sets of 
experimental data and calculated values of energy and exergy efficiencies were collected using traverse wire rib roughened absorber plate. The neural model has been developed with MLP structure using 6 parameters in the input layer and 2 parameters in the output layer. The neural model has been trained with 4 to 7 number of hidden neurons using two different types of learning algorithms, i.e., LM and SCG. The 6-6-2 neural structure with LM learning algorithm is obtained as the optimal neural model for prediction of data. The performance prediction of ANN model has been evaluated on the basis of statistical error analysis. The values of MAE, SSE, MSE and COV for thermal efficiency were obtained as $0.06220,1.3244,2.648 \mathrm{E}-2$ and 0.43471 , respectively. Similarly, these values for exergy efficiency were found to be $0.01468,0.02257,4.514 \mathrm{E}-4$ and $0.362 \mathrm{E}-1$, respectively, which are very low as desired. The values of coefficient of determination $\left(\mathrm{R}^{2}\right)$ for energy efficiency and exergy efficiency are 0.99921 and 0.95737 , respectively, which are very close to unity and thus perform accurate results of predicted values.

In view of high accuracy obtained in the predicted results of energy and exergy efficiencies of roughened solar air heater, the proposed MLP ANN model is recommended for energetic and exergetic performance analysis of any solar energy systems.

\section{ACKNOWLEDGMENTS}

The author gratefully acknowledges Department of Mechanical Engineering, National Institute of Technology, Jamshedpur, Jharkhand, India for their support in research work.

\section{CONFLICTS OF INTEREST}

The author declares that there is no conflict of interests regarding the publication of this paper.

\section{REFERENCES}

[1] Duffie, J.A., Beckman, W.A. (1991). Solar Engineering of Thermal Processes, second ed.,Wiley Publication, New York.

[2] Bhushan, B., Singh, R. (2010). A review on methodology of artificial roughness used in duct of solar air heaters, Energy, 35, 202-212. https://doi.org/10.1016/j.energy.2009.09.010

[3] Chamoli, S., Thakur, N.S., Saini,J.S. (2012). A review of turbulence promoters used in solar thermal system. Renew. Sustain. Energy Rev., 16, 3154-3175. https://doi.org/10.1016/j.rser.2012.01.021

[4] Prasad, B.N. (2013). Thermal performance of artificially roughened solar air heaters. Sol. Energy, 91, 59-67. https://doi.org/10.1016/j.solener.2013.01.014

[5] Kumar, A., Prasad, B.N., Prasad, L. (2014). Thermal performance of artificially roughened solar air heaters, M.Tech Thesis, National Institute of Technology, Jamshedpur, Jharkhand, India. 
[6] Mittal, M.K., Varshney, L. (2006). Optimal thermo hydraulic performance of a wire mesh packed solar heater. Solar Energy, 80, 1112-1120. https://doi.org/10.1016/j.solener.2005.10.004

[7] Singh, P.L., Deshpandey, B.D., Jena, P.C. (2015). Thermal performance of packed bed heat storage system for solar air heaters. Energy for sustainable Development, 29, 112-117. https://doi.org/10.1016/j.esd.2015.10.010

[8] Ajam, H., Farahat, S., Sarhaddi, F. (2005). Exergetic optimization of solar air heaters and comparison with energy analysis. Int J Thermodyn, 8(4), 183-190. http://dergipark.gov.tr/download/article-file/65674

[9] Esen, H. (2008). Experimental energy and exergy analysis of a double-flow solar air heater having different obstacles on absorber plates. Build and Environ, 43,10461054.

https://doi.org/10.1016/j.buildenv.2007.02.016

[10] Akpinar, E.K., Koçyigit, F. (2010). Experimental investigation of thermal performance of solar air heater having different obstacles on absorber plates. Int Commun Heat Mass Transfer, 37, 416-421. https://doi.org/10.1016/j.icheatmasstransfer.2009.11.007

[11] Alta, D., Bilgili, E., Ertekin, C., Yaldiz, O. (2010). Experimental investigation of three different solar air heaters: Energy and exergy analyses. Applied Energy, 87 , 2953-2973

https://doi.org/10.1016/j.apenergy.2010.04.016

[12] Bayrak, F., Oztop, H.F., Hepbasli, A. (2013). Energy and exergy analyses of porous baffles inserted solar air heaters for building applications. Energy Build, 57, 338-345. https://doi.org/10.1016/j.enbuild.2012.10.055

[13] Panwar, N., Kaushik, S., Kothari, S. (2012). A review on energy and exergy analysis of solar dying systems. Renew Sustain Energy Rev, 16(5), 2812-2819.

https://doi.org/10.1016/j.rser.2012.02.053

[14] Saidur, R., BoroumandJazi, G., Mekhlif, S., Jameel, M. (2012). Exergy analysis of solar energy applications. Renew Sustain Energy Rev, 16(1), 350-356. https://doi.org/10.1016/j.rser.2011.07.162

[15] Kumar, L., Mukesh Sarvaiya, R.M., Bhagoriya, J.L. (2012). Exergy evaluation of packed bed solar air heater. Renewable and Sustainable Energy Reviews, 16, 62626267.

https://doi.org/10.1016/j.rser.2012.04.024

[16] Park, S., Pandey, A., Tyagi, V., Tyagi, S. (2014). Energy and exergy analysis of typical renewable energy systems, Renewable and Sustainable Energy Reviews, 30, 105-123. https://doi.org/10.1016/j.rser.2013.09.011

[17] Kalogirou, S.A. (2000). Applications of artificial neural-networks for energy systems. Applied Energy, 67(1-2), 17-35. https://doi.org/10.1016/S0306-2619(00)00005-2

[18] Yang, I.H.,Yeo, M.S., Kim, K.W. (2003). Application of artificial neural network to predict the optimal start time for heating system in building. Energy Conversion and Management, 44, 2791-2809. https://doi.org/10.1016/S0196-8904(03)00044-X 
[19] Facao, J., Varga, S., Oliveira, A.C. (2004). Evaluation of the Use of Artificial Neural Networks for the Simulation of Hybrid Solar Collectors. International Journal of Green Energy, 1(3), 337-352. https://doi.org/10.1081/GE-200033649

[20] Ertunc, H.M., Hosoz, M.(2006). Artificial neural network analysis of a refrigeration system with an evaporative condenser. Applied Thermal Engineering, 26, 627-635. https://doi.org/10.1016/j.applthermaleng.2005.06.002

[21] Kalogirou, S.A. (2006). Prediction of flat-plate collector performance parameters using artificial neural networks. Solar Energy, 80, 248-259. https://doi.org/10.1016/j.solener.2005.03.003

[22] Yilmaz, S., Atik, K. (2007). Modeling of a mechanical cooling system with variable cooling capacity by using artificial neural network. Applied Thermal Engineering, 27, 2308-2313. https://doi.org/10.1016/j.applthermaleng.2007.01.030

[23] Sozen, A., Menlik, T., Unvar, S. (2008). Determination of efficiency of flat-plate solar collectors using neural network approach. Expert Syst. Appl., 35(4), 15331539. https://doi.org/10.1016/j.eswa.2007.08.080

[24] Kurt, H., Atik, K., Ozkaymak, M., Recebli, Z. (2008). Thermal performance parameters estimation of hot box type solar cooker by using artificial neural network. International Journal of Thermal Sciences, 47, 192-200. https://doi.org/10.1016/j.ijthermalsci.2007.02.007

[25] Caner, M., Gedik, E., Kecebas, A. (2011). Investigation on thermal performance calculation of two type solar air collectors using artificial neural network. Expert Syst. Appl., 38(3), 1668-1674. https://doi.org/10.1016/j.eswa.2010.07.090

[26] Nazghelichi, T., Aghbashlo, M., Kianmehr, M.H., Omid, M. (2011). Prediction of Energy and Exergy of Carrot Cubes in a Fluidized Bed Dryer by Artificial Neural Networks. Drying Technology: An International Journal, 29(3), 295-307. https://doi.org/10.1080/07373937.2010.494237

[27] Aghbashlo, M., Mobli, H., Rafiee, S., Madadlou, A. (2012). The use of artificial neural network to predict exergetic performance of spray drying process: A preliminary study. Computers and Electronics in Agriculture, 88, 32-43. https://doi.org/10.1016/j.compag.2012.06.007

[28] Benli, H. (2013). Determination of thermal performance calculation of two different types solar air collectors with the use of artificial neural networks. Int. J. of Heat and Mass Transfer, 60, 1-7. https://doi.org/10.1016/j.ijheatmasstransfer.2012.12.042

[29] Kalogirou, S.A., Mathioulakis, E., Belessiotis, V. (2014). Artificial neural networks for the performance prediction of large solar systems. Renewable Energy, 63, 90-97. https://doi.org/10.1016/i.renene.2013.08.049

[30] Hamdan, M. A., Abdelhafez, E. A., Hamdan, A. M., and Khalil, R. A. H. (2016). Heat Transfer Analysis of a Flat-Plate Solar Air Collector by Using an Artificial Neural Network. Journal of Infrastructure Systems, 22(4), A4014004. DOI: 10.1061/(ASCE)IS.1943-555X.0000213.

[31] Jani, D.B., Mishra, M., Sahoo, P.K. (2016). Performance prediction of solid desiccant - vapor compression hybrid air-conditioning system using artificial neural network. Energy, 103, 618-629. http://dx.doi.org/10.1016/j.energy.2016.03.014

[32] Jani, D.B., Mishra, M., Sahoo, P.K. (2016). Performance prediction of rotary solid desiccant dehumidifier in hybrid air-conditioning system using artificial neural network. Appl Therm Eng, 98, 1091-1103. 
http://dx.doi.org/10.1016/j.applthermaleng.2015.12.112

[33] Ghritlahre, H.K., Prasad, R.K. (2017). Prediction of thermal performance of unidirectional flow porous bed solar air heater with optimal training function using Artificial Neural Network. Energy Procedia, 109, 369 - 376. https://doi.org/10.1016/j.egypro.2017.03.033

[34] Ghritlahre, H.K. ,Prasad, R.K. (2017). Energetic and exergetic performance prediction of roughened solar air heater using artificial neural network. Ciência $e$ Técnica Vitivinícola, 32 (11), 2-24.

[35] Ghritlahre, H.K. , Prasad, R.K. (2018). Application of ANN technique to predict the performance of solar collector systems - A review. Renewable and Sustainable Energy Reviews, 84, 75-88. https://doi.org/10.1016/j.rser.2018.01.001

[36] Ghritlahre, H.K., Prasad, R.K. (2018). Exergetic Performance Prediction of roughened Solar Air Heater Using Artificial Neural Network. Strojniški vestnik Journal of Mechanical Engineering, 64 (3), 195-206. http://dx.doi.org/10.5545/sv-jme.2017.4575

[37] Ghritlahre, H.K., Prasad, R.K. (2018). Development of Optimal ANN Model to Estimate the Thermal Performance of Roughened Solar Air Heater Using Two different Learning Algorithms. Annals of Data Science, 5(3),453-467. https://doi.org/10.1007/s40745-018-0146-3

[38] Ghritlahre, H.K., Prasad, R.K. (2018). Investigation on heat transfer characteristics of roughened solar air heater using ANN technique. International Journal of Heat and Technology, 36 (1), 102-110. https://doi.org/10.18280/ijht.360114

[39] Ghritlahre, H.K., Prasad, R.K. (2018). Investigation of thermal performance of unidirectional flow porous bed solar air heater using MLP, GRNN, and RBF models of ANN technique. Thermal Science and Engineering Progress, 6, 226-235. https://doi.org/10.1016/j.tsep.2018.04.006

[40] Ghritlahre, H.K., Prasad, R.K. (2018). Exergetic performance prediction of solar air heater using MLP, GRNN and RBF models of artificial neural network technique. Journal of Environmental Management, 223, 566-575. https://doi.org/10.1016/j.jenvman.2018.06.033

[41] Haykin, S. (1994). Neural networks, a comprehensive foundation, New Jersey: Prentice- Hall.

[42] Cengel, Y.A., Boles, M.A. (2006). Thermodynamics: an engineering approach. 5th ed. New York: McGraw-Hill.

Article copyright: (C) 2018 Harish K. Ghritlahre. This is an open access article distributed under the terms of the Creative Commons Attribution 4.0 International License, which permits unrestricted use and distribution provided the original author and source are credited. 